\title{
Recent trends in the incidence of multiple births and associated mortality in England and Wales
}

\author{
Alistair Dunn, Alison Macfarlane
}

\begin{abstract}
Aim-To review trends in multiple births and associated mortality in England and Wales since 1975, in the light of trends for earlier years; to assess, within the limitations of the available data, the extent of any association between multiple birth rates and assisted conception and drugs used for subfertility.

Methods-Data collected routinely in England and Wales, between 1975 and 1994, were retrospectively reviewed. These comprised Office of Population Censuses and Surveys (OPCS) data collected at the registration of live and stillbirths and deaths occurring under the age of 1 year in England and Wales from 1975 onwards. Department of Health data about NHS prescriptions dispensed outside hospitals within England for drugs which could be used in the medical management of subfertility were also included.
\end{abstract}

Results-The proportion of pregnancies that resulted in a registered multiple birth increased from a low of 9.9 per thousand in 1975 to 13.6 per thousand in 1994. Up to 1992, the increase was seen in all age groups except for women under 20 , with the most substantial increase being in women aged 35 to 39 . The rise in the rate of triplet and other higher order births was much steeper than that for all multiple births, increasing from 0.13 sets of triplets per thousand maternities in 1975 , to 0.41 in 1994. Prescriptions dispensed for selected drugs that may be used for the medical management of subfertility and assisted conception became more common over this period. The fragmented nature of the data precluded direct comparison with changes in multiple birth rates, however.

Conclusions-Although the causes of the rise since 1980 in multiple birth rates in general, and the dramatic rise in the triplet rate in particular, cannot be ascertained or quantified directly from routinely collected data, drugs used for subfertility and more recently, assisted conception, probably had a major role. (Arch Dis Child 1996;75:F10-F19)

Keywords: multiple birth, stillbirth, infant mortality, assisted conception, ovarian stimulants, time trends.
Multiple births account for only about $1 \%$ of deliveries in England and Wales, but they contribute disproportionately to the overall numbers of stillbirths, infant deaths, and very low birthweight babies.' ${ }^{1}$ Children from multiple births, particularly those from triplet and higher order births, place much greater demands on their parents and the health and social services than singletons. ${ }^{2}$ Multiple maternities are also associated with higher rates of morbidity and mortality in the mother throughout pregnancy and birth, and in the babies during the first weeks of life. ${ }^{23}$

An earlier article from the National Perinatal Epidemiology Unit (NPEU) and the Office of Population Censuses and Surveys (OPCS) reviewed trends from the late 1930 s to the mid 1980s. ${ }^{4}$ This showed that after a period of decline, multiple birth rates started to rise in England and Wales during the early 1980s. This increase has continued steadily in the case of twins. In contrast, there has been a much more dramatic rise in rates of triplet and higher order births, with a threefold increase in the rate during the 1980 s. $^{5}$ Similar trends have been observed elsewhere-for example, in Scotland, ${ }^{6}$ the United States, ${ }^{78}$ Canada, ${ }^{9} \mathrm{Ja}$ pan, ${ }^{10}$ Australia, ${ }^{11}$ east Flanders (Belgium), ${ }^{12}$ France, ${ }^{13}$ Italy, ${ }^{14}$ and most other Western European countries. (Masuy-Stoobant G. Santé et mortalité infantile en Europe. Victoires d'hier et enjeux de demain. Paper presented at Chaire Quetelet, Louvain-la-Neuve, Belgium, September 1994).

The rise in multiple birth rates has coincided with the increasing use of drugs used in the medical management of subfertility, and the development and increasing availability of assisted conception. Where data are available, a clear link can be seen between the increasing use of assisted conception and the rise in multiple births - in Australia, for example..$^{15}$ Most other countries, England and Wales included, do not have a comprehensive system of data which enables this to be monitored directly year by year.

Other factors may also have contributed to the increase. The average age of childbearing has increased. As the multiple birth rate is higher among older women than younger ones, this may also have contributed to the rise in multiple births. Older women may also be more likely to seek help for fertility problems. ${ }^{16}$ Multiple births are also more likely among women of higher parity. ${ }^{17}$ 
We update previous evidence ${ }^{4}$ by reviewing the trends in multiple births and associated mortality from 1975. We also attempt to use available data to assess the impact of assisted conception and drugs used in the medical management of subfertility on the numbers of multiple maternities.

\section{Methods}

The analysis took the form of a retrospective review of national vital statistics for England and Wales. Confidence intervals, $\chi^{2}$ tests, and $\chi^{2}$ tests for trend were calculated using the computer package EpiInfo, version 6.02. ${ }^{18}$

Numbers of births and deaths were extracted from OPCS published birth and death registration data for England and Wales. Since July 1938, multiple births have been coded as such for analysis. The exception is data for births in 1981, when multiplicity was not coded following industrial action by local registrars of births and deaths.

Registration data may underestimate the extent of multiple births. Although live births at any gestation should be registered, the law is different for stillbirths. Before October 1992, all fetal deaths at $\mathbf{2 8}$ or more completed weeks of gestation should have been registered as stillbirths. On 1 October 1992, this limit was lowered to 24 completed weeks of gestation. The numbers of stillbirths in 1992 and 1993 quoted in this paper are those which meet the pre-October 1992 criterion of 28 or more completed weeks of gestation. If a set includes a fetal death that does not satisfy the criteria for registration as a stillbirth, then only the live births within the set will be registered.

Since 1975, OPCS has routinely linked records of each death under the age of 1 year with the record containing the data collected at the corresponding birth registration. These data include the ages of the parents, the place of delivery, and whether the baby was one of a multiple birth. ${ }^{1}$ The data presented here come from the birth cohort data sets, which contain data about deaths of babies born in a given year. Although gestational age is recorded on stillbirth registrations, this information is not collected by OPCS for live births. Data on gestational age are recorded in the Maternity Hospital Episode System, but these data were still too incomplete to be used for this analysis. ${ }^{5}$ Gestational age is also recorded on notifications of live and stillbirths to district health authorities, but these are not analysed at national level.

Collection of data about birthweight on live birth registrations started in 1975, but before 1982 these data were relatively incomplete. In 1983 OPCS was able to obtain the birthweights of about $99.8 \%$ of live births. Unfortunately, there was a deterioration in the completeness of these data during 1989. From 1990 onwards, just under $4 \%$ of birthweight data were missing. There was a slight improvement in 1993, though $3.3 \%$ of birthweight data were still missing. The numbers of babies recorded as very low birthweight by OPCS may also be overestimated. One such source of error is the incorrect coding of birthweights recorded in units other than grams. For example, babies whose birthweight was recorded in kilograms instead of grams at registration may be incorrectly coded on OPCS records. For example, a baby weighing $3500 \mathrm{~g}$ whose birthweight is recorded as $3.5 \mathrm{~kg}$ may be coded incorrectly as $35 \mathrm{~g}$ or $305 \mathrm{~g}$. OPCS records the date of birth of all mothers at birth registration, but records parity only for married women and restricts this to "...the number of previous live or still born children by the present or any former husband, as stated at birth registration." The proportion of births that take place outside marriage has been increasing, ${ }^{19}$ reaching $31.2 \%$ in 1992 . As a result, the parity data defined in this way are increasingly incomplete and have not been used in this paper.

Except where otherwise stated, this paper is based on data in the public domain at the time of writing. This includes data on total numbers of multiple births and maternities for 1994, more detailed tabulations on births up to $1993,{ }^{19}$ and analyses of linked birth and death data for years up to $1992 .{ }^{1}$

The Human Fertilisation and Embryology Authority (HFEA) is responsible for the licensing of centres in the United Kingdom that offer in vitro fertilisation (IVF), donor insemination, and donor eggs. As with the voluntary bodies that preceded it, the HFEA collects data about the numbers of IVF and, if donated gametes are used, gamete intrafallopian transfer (GIFT) procedures in clinics licensed for IVF, and the resulting numbers of pregnancies and births. ${ }^{20}$

Unfortunately, the HFEA data are incomplete in several ways. Units that provide GIFT and related procedures, where donor gametes are not being used, but not IVF, do not have to be licensed, and are therefore not included in the statistics. The HFEA publishes data on numbers of treatment cycles, maternities, and live births. Although it collects data on whether a pregnancy led to a live or stillbirth, published analyses contain no indication of whether these were registrable in England and Wales. IVF and GIFT clinics also cater for people living outside the United Kingdom but neither the usual country of residence of the parents, nor the country of birth of any resulting babies are recorded. Direct comparisons with the numbers of births registered in England and Wales cannot therefore be made. Occasionally babies born in England and Wales have been conceived after undergoing IVF or other procedures outside the United Kingdom. They too, will not have been included in the HFEA statistics.

No data are collected routinely about the numbers of women who take drugs which may be used in the medical management of subfertility but who are not undergoing assisted conception. The Department of Health obtains data from the Prescription Pricing Authority about the numbers of prescriptions dispensed. These data summarise the numbers of prescriptions dispensed by community pharmacists, dispensing doctors, and for personal 
Table 1 Numbers of singleton and multiple maternities, England and Wales, 1975-94

\begin{tabular}{|c|c|c|c|c|c|c|c|c|c|c|c|c|}
\hline \multirow[b]{3}{*}{ Year } & \multirow[b]{3}{*}{ All } & \multirow[b]{3}{*}{ Singleton } & \multirow{2}{*}{\multicolumn{2}{|c|}{ All }} & \multirow{2}{*}{\multicolumn{2}{|c|}{ Twins }} & \multicolumn{6}{|c|}{ Multiple maternities } \\
\hline & & & & & & & \multirow{2}{*}{$\begin{array}{l}\text { Triplets } \\
\text { No }\end{array}$} & \multirow{2}{*}{$\begin{array}{l}\text { Quadruplets } \\
\text { No }\end{array}$} & \multirow{2}{*}{$\begin{array}{l}\text { Quintuplets } \\
\text { No }\end{array}$} & \multirow{2}{*}{$\begin{array}{l}\text { Sextuplets } \\
\text { and above }\end{array}$} & \multicolumn{2}{|c|}{ Triplets and above } \\
\hline & & & No & Rate & No & Rate & & & & & No & Rate \\
\hline 1975 & 603666 & 597678 & 5988 & 9.9 & 5909 & 9.8 & 72 & 7 & 0 & 0 & 79 & 0.13 \\
\hline 1976 & 584263 & 578642 & 5621 & 9.6 & 5538 & 9.5 & 76 & 4 & 2 & 1 & 83 & 0.14 \\
\hline 1977 & 569073 & 563554 & 5519 & 9.7 & 5449 & 9.6 & 68 & 2 & 0 & 0 & 70 & 0.12 \\
\hline 1978 & 595515 & 589585 & 5930 & 10.0 & 5859 & 9.8 & 62 & 8 & 1 & 0 & 71 & 0.12 \\
\hline 1979 & 636884 & 630703 & 6181 & 9.7 & 6099 & 9.6 & 76 & 6 & 0 & 0 & 82 & 0.13 \\
\hline 1980 & 654501 & 648097 & 6404 & 9.8 & 6308 & 9.6 & 91 & 4 & 1 & 0 & 96 & 0.15 \\
\hline 1981 & 632350 & & & & & & & & & & & \\
\hline 1982 & 623511 & 617234 & 6277 & 10.1 & 6201 & 9.9 & 70 & 6 & 0 & 0 & 76 & 0.12 \\
\hline 1983 & 626277 & 619890 & 6387 & 10.2 & 6293 & 10.0 & 89 & 4 & 0 & 1 & 94 & 0.15 \\
\hline 1984 & 633965 & 627559 & 6406 & 10.1 & 6321 & 10.0 & 80 & 5 & 0 & 0 & 85 & 0.13 \\
\hline 1985 & 653142 & 646339 & 6803 & 10.4 & 6700 & 10.3 & 93 & 7 & 2 & 1 & 103 & 0.16 \\
\hline 1986 & 657308 & 650203 & 7105 & 10.8 & 6969 & 10.6 & 123 & 10 & 2 & 1 & 136 & 0.21 \\
\hline 1987 & 677467 & 670147 & 7320 & 10.8 & 7186 & 10.6 & 125 & 7 & 1 & 1 & 134 & 0.20 \\
\hline 1988 & 689153 & 681531 & 7622 & 11.1 & 7452 & 10.8 & 157 & 12 & 1 & 0 & 170 & 0.25 \\
\hline 1989 & 682979 & 675205 & 7774 & 11.4 & 7579 & 11.1 & 183 & 11 & 1 & 0 & 195 & 0.29 \\
\hline 1990 & 701030 & 692885 & 8145 & 11.6 & 7934 & 11.3 & 201 & 10 & 0 & 0 & 211 & 0.30 \\
\hline 1991 & 693857 & 685477 & 8380 & 12.1 & 8160 & 11.8 & 208 & 10 & 2 & 0 & 220 & 0.32 \\
\hline 1992 & 683854 & 675329 & 8525 & 12.5 & 8314 & 12.2 & 202 & 8 & 1 & 0 & 211 & 0.31 \\
\hline 1993 & 668511 & 659962 & 8549 & 12.8 & 8302 & 12.4 & 234 & 12 & 0 & 1 & 247 & 0.37 \\
\hline 1994 & 659126 & 650675 & 8719 & 13.2 & 8451 & 12.8 & 260 & 8 & 0 & 0 & 268 & 0.41 \\
\hline
\end{tabular}

Source: OPCS birth statistics

Table 2 Number of multiple maternities by age of mother, England and Wales, 1993

\begin{tabular}{lccccc}
\hline & \multicolumn{3}{c}{ Multiple maternities } \\
\cline { 3 - 6 } Mother's age & All maternities & Numbers & Rate & Relative risk & $95 \%$ CI \\
\hline Under 20 & 45160 & 286 & 6.3 & 1.0 & \\
$20-24$ & 151426 & 1407 & 9.3 & 1.5 & $1.3-1.7$ \\
$25-29$ & 234267 & 2800 & 12.0 & 1.9 & $1.7-2.1$ \\
$30-34$ & 169097 & 2794 & 16.5 & 2.6 & $2.3-2.9$ \\
$35-39$ & 58088 & 1096 & 18.9 & 2.9 & $2.6-3.4$ \\
$40-44$ & 9935 & 154 & 15.5 & 2.4 & $2.0-3.0$ \\
45 and over & 538 & 12 & 22.3 & 3.5 & $2.0-6.1$ \\
Total & 668511 & 8549 & 12.8 & & \\
\end{tabular}

Source: OPCS Birth Statistics, Series FM1

administration within England; no information was available for drugs dispensed in hospital or privately.

The Department of Health provided data for the numbers of prescriptions dispensed in England for chorionic gonadotrophin, clomiphene citrate, cyclofenil, gonadorelin (Fertiral only), menotrophin, urofollitrophin, for each year since 1980 . The data record the number of prescriptions dispensed, but do not describe the number of women treated or the number of courses of treatment each received. Furthermore, the method of processing these data was

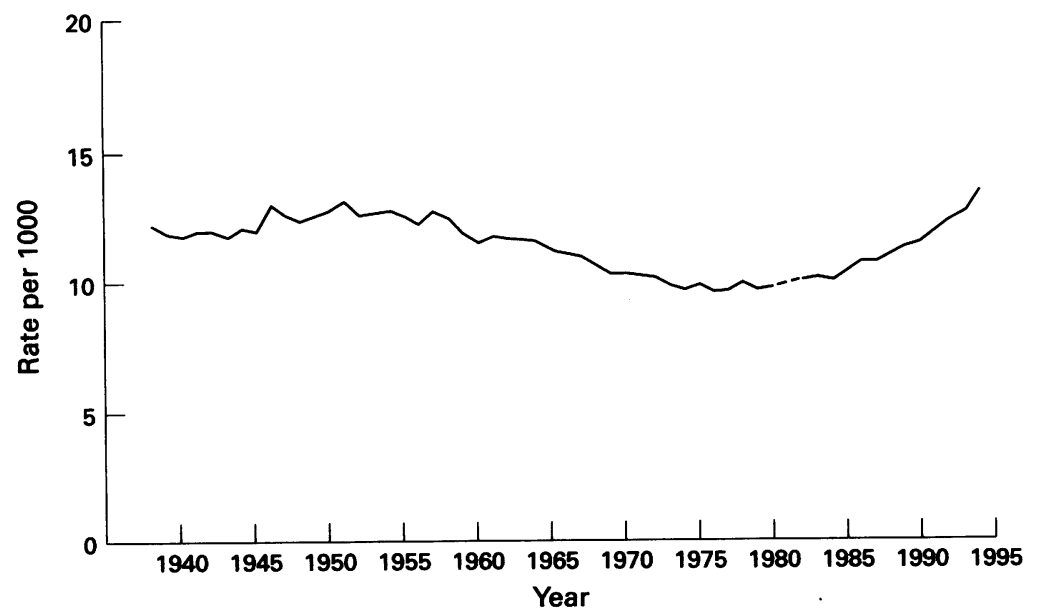

Figure 1 Multiple maternities per thousand maternities, England and Wales, 1938-94. Source: OPCS annual statistics, Series FM1 Birth Statistics, England and Wales. changed in 1991. As a result, data for years before 1991 are not directly comparable with those for subsequent years.

\section{TRENDS IN INCIDENCE OF MULTIPLE BIRTH} All multiple births

The rates of multiple maternities-that is, the proportion of maternities that lead to more than one registered birth-are shown in fig 1 . The proportion of maternities resulting in a multiple birth steadily decreased afterthe early 1950 s from a high of 13.2 multiple maternities per thousand maternities in 1951 , to a low of 9.6 per thousand maternities in 1976. Since 1977 , the rate of multiple maternities has been increasing (table 1). This rate has now returned to levels recorded in the 1950 s, reaching 13.6 multiple maternities per thousand total maternities in 1994.

Age of mother

As in previous years, the rate of multiple births in 1992 was lowest for women under 20 and highest for women over 35 . The exception to this was the rate among the very small number of maternities to women aged 40 and over. Table 2 shows that this was lower than that for women in their 30s, and women aged 35 to 39 are far more likely to have a multiple pregnancy than women under 35 .

In general, an increasing proportion of maternities are to older women at a time when the numbers of women in this age group have 
Table 3 Multiple maternities per thousand maternities by age of mother, England and Wales, 1975-93

\begin{tabular}{rllllllr}
\hline & & & & & & 40 & \\
Year & 20 & 24 & 29 & 34 & 39 & $\begin{array}{l}\text { and } \\
\text { over }\end{array}$ & \multicolumn{1}{l}{$\begin{array}{l}\text { All } \\
\text { ages }\end{array}$} \\
\hline 1975 & 6.1 & 8.3 & 10.4 & 13.3 & 14.5 & 14.6 & 9.9 \\
1976 & 6.2 & 7.7 & 10.5 & 12.4 & 13.4 & 11.1 & 9.6 \\
1977 & 5.5 & 7.9 & 10.3 & 12.7 & 13.6 & 12.4 & 9.7 \\
1978 & 5.8 & 8.2 & 10.6 & 12.4 & 15.0 & 10.8 & 10.0 \\
1979 & 5.9 & 7.8 & 10.3 & 12.4 & 13.6 & 11.1 & 9.7 \\
1980 & 5.7 & 7.8 & 10.4 & 12.5 & 14.4 & 11.3 & 9.8 \\
1981 & & & & & & & \\
1982 & 6.1 & 7.9 & 10.7 & 12.8 & 14.8 & 11.6 & 10.1 \\
1983 & 5.8 & 8.5 & 10.5 & 13.0 & 14.4 & 9.4 & 10.2 \\
1984 & 5.2 & 8.3 & 10.5 & 12.5 & 15.4 & 13.8 & 10.1 \\
1985 & 5.6 & 8.7 & 10.5 & 13.0 & 16.1 & 12.9 & 10.4 \\
1986 & 6.5 & 8.5 & 11.0 & 13.7 & 16.8 & 11.8 & 10.8 \\
1987 & 5.9 & 8.3 & 11.3 & 13.7 & 16.6 & 12.5 & 10.8 \\
1988 & 5.7 & 8.8 & 11.2 & 14.1 & 16.8 & 14.0 & 11.1 \\
1989 & 6.2 & 8.9 & 11.4 & 14.7 & 16.3 & 13.0 & 11.4 \\
1990 & 6.0 & 8.9 & 11.5 & 14.8 & 18.0 & 11.7 & 11.6 \\
1991 & 5.7 & 9.0 & 11.5 & 16.1 & 18.8 & 13.9 & 12.1 \\
1992 & 5.7 & 8.9 & 12.2 & 15.9 & 19.1 & 14.8 & 12.5 \\
1993 & 6.3 & 9.3 & 12.0 & 16.5 & 18.9 & 15.9 & 12.8 \\
\hline
\end{tabular}

Source: OPCS Birth Statistics, Series FM1

also been increasing. The proportion of all maternities to women aged 30 or more increased from $20 \%$ in 1975 to $26 \%$ in 1982 , and to $34 \%$ in 1992 . The rise in age specific fertility and in changes in population structure may partly explain the recent rise in the overall rate of multiple births. Nevertheless, there were still substantial increases in the proportion of multiple maternities within each age group, except for women aged under 20 and those aged 40 and over (fig 2) (table 3).

Among women aged under 20, the rate of multiple maternities has remained both low and constant since 1938. Over the same period, there have been considerable changes in the proportions of multiple births among maternities to older women. During the 1980 s, the rate of multiple maternities showed the most pronounced increase among women aged 35 to 39 . Here the rate increased from 14.4 multiple maternities per thousand total maternities in 1980 to 19.1 in 1992, an increase of $33 \%$. The multiple maternity rate for women under 20 remained unchanged. In contrast, there was a $14 \%$ increase among women aged 20 to 24 , a $17 \%$ increase among women aged 25 to 29 , and a $27 \%$ increase among women

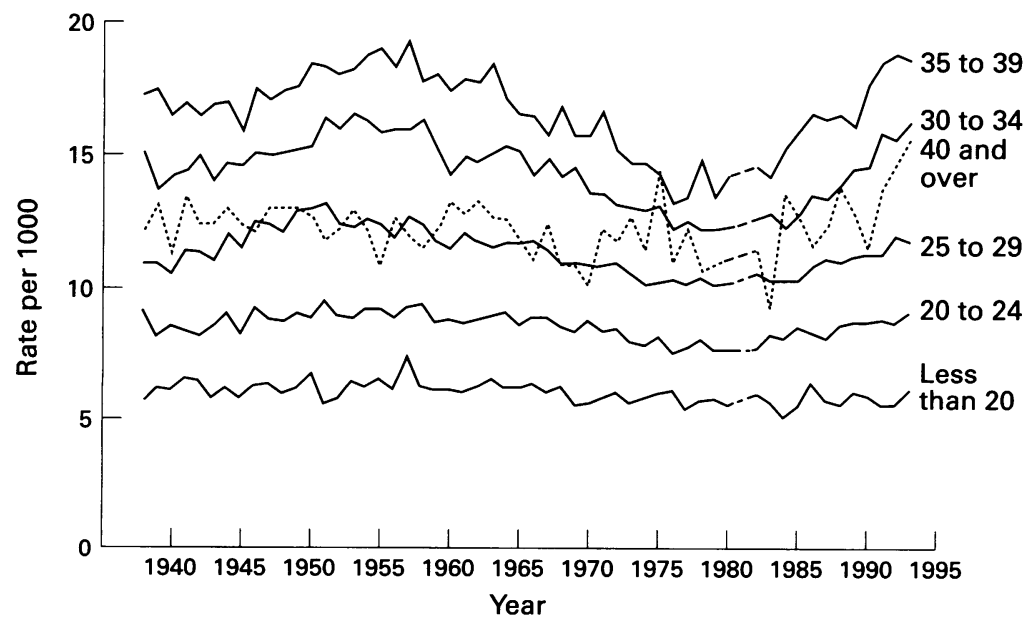

Figure 2 Multiple maternities per thousand maternities by age of mother, England and Wales, 1938-93. Source: OPCS annual statistics, Series FM1 Birth Statistics, England and Wales.
Table 4 Percentage of multiple and singleton live and stillbirths with birthweights under 2500, England and Wales, 1980-91

\begin{tabular}{llllll}
\hline & \multicolumn{2}{l}{ Multiple births } & & \multicolumn{2}{c}{ Singleton births } \\
\cline { 2 - 3 } \cline { 6 - 6 } Year & Still & Live & & Still & Live \\
\hline 1980 & 87.5 & 51.6 & & 64.5 & 5.6 \\
1981 & & & & \\
1982 & 83.9 & 50.9 & & 61.0 & 5.8 \\
1983 & 91.0 & 51.4 & & 73.4 & 5.8 \\
1984 & 87.8 & 51.3 & & 61.2 & 5.9 \\
1985 & 83.2 & 52.3 & & 60.9 & 5.9 \\
1986 & 91.5 & 53.0 & & 60.4 & 5.9 \\
1987 & 88.4 & 53.1 & & 59.9 & 5.8 \\
1988 & 89.2 & 52.0 & & 58.1 & 5.6 \\
1989 & 87.6 & 52.9 & & 57.8 & 5.7 \\
1990 & 91.4 & 52.8 & & 59.0 & 5.7 \\
1991 & 89.1 & 53.8 & & 57.3 & 5.7 \\
\hline
\end{tabular}

Source: OPCS Birth Statistics, Series FM1

aged 30 to 34 . The rates in each age group were comparable with those in the early 1950 s.

\section{Birthweight}

Babies born in a multiple pregnancy tend to have lower birthweights than singletons (table 4). In $1991,54 \%$ of liveborn babies and $89 \%$ of stillbirths with stated birthweights in multiple maternities weighed less than $2500 \mathrm{~g}$, compared with $6 \%$ and $57 \%$ of singleton births, respectively. Without data on gestational age, it was not possible to assess the extent to which the differences in birthweight are associated with differences in gestational age, and to what extent they reflect the differences between singleton and multiple births.

Among babies born alive in multiple births, the proportion weighing under $2500 \mathrm{~g}$ has increased slightly, from $51.5 \%$ of babies with a stated birthweight in 1980 to $53.8 \%$ in 1991 . For singleton births, this proportion has decreased, but only slightly, over the same period, from $5.9 \%$ to $5.7 \%$. Similar trends were seen in the much smaller proportions of babies with a birthweight under $1500 \mathrm{~g}$, with a rise from $7.4-8.8 \%$ for multiple births, and a slight change from $0.6-0.8 \%$ for singleton births.

\section{Twins}

Even with the rise in triplet and higher order births, most multiple births are still twins. Twins accounted for $97 \%$ of all multiple maternities in 1994 and trends in twinning were similar to those for all multiple maternities. The proportion of twin maternities fell from about 12 per thousand maternities in the late 1950 s to a low of 9.5 in 1976 . They have since increased, reaching 12.4 sets of twins per thousand in 1993 and 13.2 in 1994.

For each twin registered, OPCS records whether the baby was part of a set with two male babies, two female babies, or one of each. A feature of the rise in multiple births is a recent increase in the proportion of maternities leading to twins of different sex. The proportion of sets of different sex babies from twin maternities fell from $30 \%$ of all sets of twin maternities in 1974 , to $28 \%$ in 1982 , then increased again to $32 \%$ in 1992 .

Zygosity of multiple births is not recorded at birth registration, but the data about numbers of unlike and like sexed twins described above 
Table 5 Numbers of sets of like and unlike sex, and estimated numbers of monozygotic and dizygotic live and stillborn twins, England and Wales, $1975-93$

\begin{tabular}{|c|c|c|c|c|c|c|c|c|}
\hline \multirow[b]{2}{*}{ Year } & \multirow[b]{2}{*}{$M M$} & \multirow[b]{2}{*}{$F F$} & \multicolumn{3}{|c|}{ Number of sets } & \multicolumn{2}{|c|}{ Estimated number of sets } & \multirow{2}{*}{$\begin{array}{l}\text { Ratio of } \\
\text { monozygotic to } \\
\text { dizygotic }\end{array}$} \\
\hline & & & Same sex & Different sex & Total & Dizygotic & Monozygotic & \\
\hline 1975 & 2021 & 2016 & 4037 & 1872 & 5909 & 3744 & 2165 & $1: 1.7$ \\
\hline 1976 & 1954 & 1936 & 3890 & 1648 & 5538 & 3296 & 2242 & $1: 1.5$ \\
\hline 1977 & 2035 & 1845 & 3880 & 1596 & 5449 & 3138 & 2311 & $1: 1.4$ \\
\hline 1978 & 2171 & 2030 & 4201 & 1658 & 5859 & 3316 & 2543 & $1: 1.3$ \\
\hline 1979 & 2257 & 2138 & 4395 & 1704 & 6099 & 3408 & 2691 & $1: 1.3$ \\
\hline 1980 & 2207 & 2224 & 4431 & 1877 & 6308 & 3754 & 2554 & $1: 1.5$ \\
\hline \multicolumn{9}{|l|}{1981} \\
\hline 1982 & 2256 & 2183 & 4439 & 1762 & 6201 & 3524 & 2677 & $1: 1.3$ \\
\hline 1983 & 2204 & 2216 & 4420 & 1873 & 6293 & 3746 & 2547 & $1: 1.5$ \\
\hline 1984 & 2265 & 2234 & 4499 & 1822 & 6321 & 3644 & 2677 & $1: 1.4$ \\
\hline 1985 & 2375 & 2400 & 4775 & 1925 & 6700 & 3850 & 2850 & $1: 1.4$ \\
\hline 1986 & 2450 & 2424 & 4874 & 2095 & 6969 & 4190 & 2779 & $1: 1.5$ \\
\hline 1987 & 2534 & 2478 & 5012 & 2174 & 7186 & 4348 & 2838 & $1: 1.5$ \\
\hline 1988 & 2604 & 2623 & 5227 & 2225 & 7452 & 4450 & 3002 & $1: 1.5$ \\
\hline 1989 & 2562 & 2691 & 5253 & 2326 & 7579 & 4652 & 2927 & $1: 1.6$ \\
\hline 1990 & 2796 & 2766 & 5562 & 2372 & 7934 & 4744 & 3190 & $1: 1.5$ \\
\hline 1991 & 2733 & 2836 & 5569 & 2591 & 8160 & 5182 & 2978 & $1: 1.7$ \\
\hline 1992 & 2838 & 2782 & 5620 & 2694 & 8314 & 5388 & 2926 & $1: 1.8$ \\
\hline 1993 & 2855 & 2782 & 5637 & 2665 & 8302 & 5330 & 2972 & $1: 1.8$ \\
\hline
\end{tabular}

Source: OPCS Birth Statistics, Series FM1

can be used to produce estimates of the numbers of monozygotic and dizygotic twins. Weinberg's method, ${ }^{21}$ which dates back to 1901 , assumes that the number of unlike sex dizygotic twins equals the number of like sex dizygotic twins born in the same period. Under this assumption, the number of monozygotic twins can be estimated by subtracting twice the

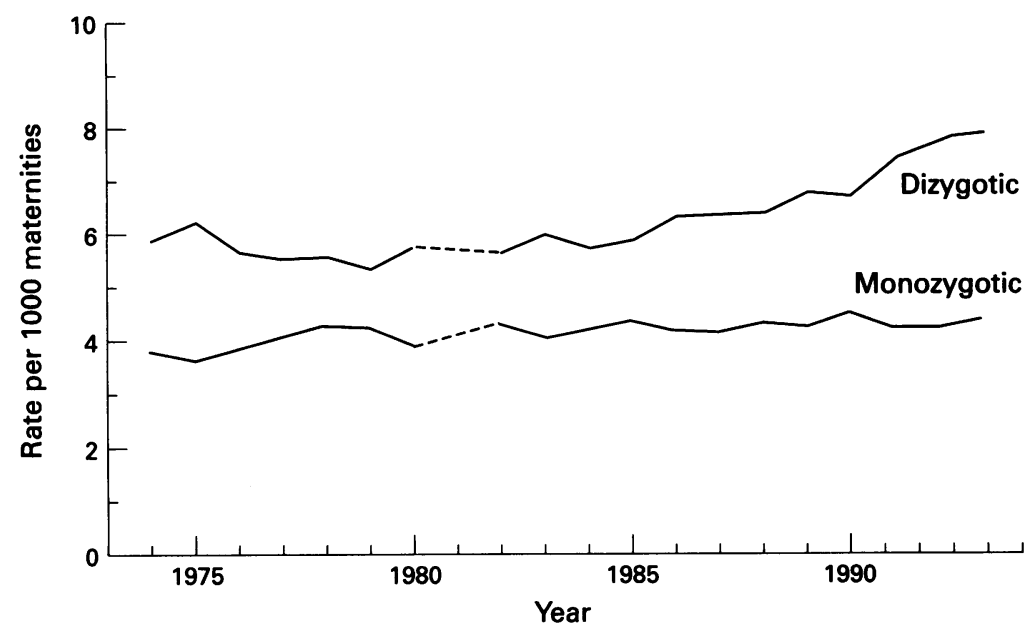

Figure 3 Estimated rates of monozygotic and dizygotic twining, England and Wales, 1974-93. Source: OPCS annual statistics, Series DH3, England and Wales.

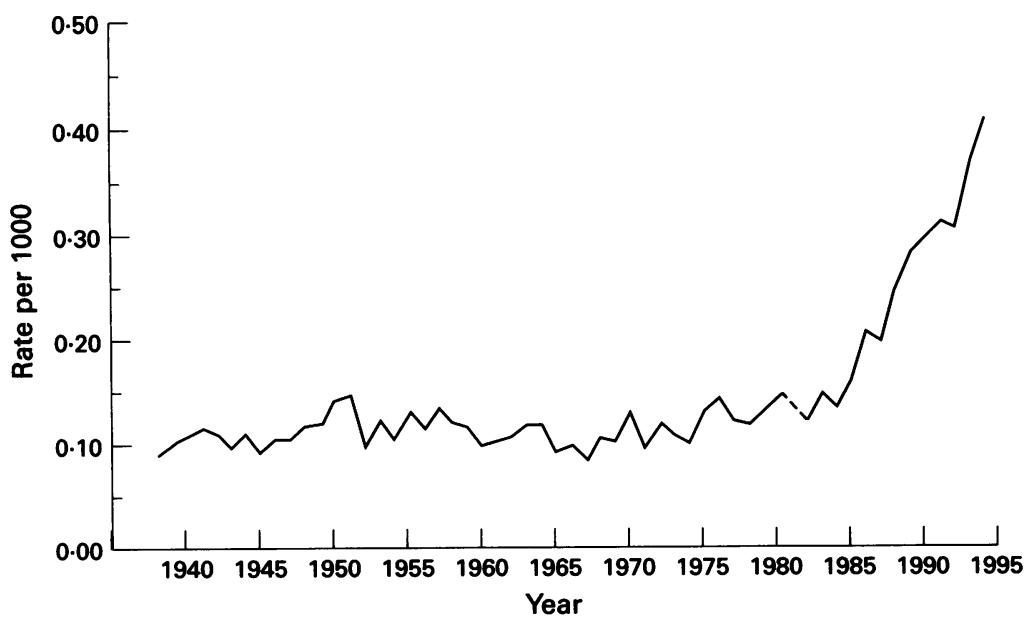

Figure 4 Triplet and other higher order births per thousand maternities, England and Wales, 1938-94. Source: OPCS annual statistics, Series FM1 Birth Statistics, England and Wales, number of unlike sex twins from the total number of like sex twins. These estimates are shown in fig 3. The numbers of like sex and unlike sex twin maternities are set out in table 5. The validity of Weinberg's method to estimate the number of monozygotic and dizygotic twins has been disputed, ${ }^{22-24}$ but the estimated numbers are shown here as a pointer to possible factors influencing the changes in the rate of twin maternities.

The estimated numbers of monozygotic and dizygotic twins have both increased at similar rates, though the ratio of monozygotic to dizygotic twins has changed only marginally. Estimated numbers of dizygotic twins accounted for $63 \%$ of all twins in 1975 , decreasing to $57 \%$ in 1982 , and increasing again to $65 \%$ in 1993 .

\section{Triplets and other higher order births}

The proportion of triplet maternities has risen dramatically in recent years (fig 4) with a threefold increase in the rate of triplets since the mid 1970 s. After a rise from 0.15 sets of triplets per thousand maternities in 1980 to 0.32 in 1991, there was a temporary halt. The rate then started to rise again, reaching 0.41 sets of triplets per thousand maternities in 1994. The numbers involved are too small to produce reliable age specific rates, but the proportion of triplet births to women aged 35 and over rose from $9 \%$ in 1980 to $18 \%$ in 1993.

MORTALITY

Babies from multiple births tend to be of lower birthweight and born at lower gestational ages than singleton babies. Taken as a whole, they therefore have a higher rate of stillbirth or death in the first year of life. ${ }^{1}$

Stillbirth and infant mortality rates for England and Wales have been routinely tabulated separately for singleton and multiple births since linkage began in 1975. Birthweight specific mortality rates are available for years from 1980 onwards. Data for 1980 show extremely high mortality rates that are considerably higher than those for 1982, the next year for which data are available. Moreover, more than $13 \%$ of birthweights in 1980 were coded 
Table 6 Stillbirth, early neonatal and infant mortality rates for multiple and singleton births by birthweight, England and Wales, 1982-91

\begin{tabular}{|c|c|c|c|c|c|c|c|}
\hline \multirow[b]{2}{*}{ Birthweight (g) } & \multirow[b]{2}{*}{ Year of birth } & \multicolumn{2}{|c|}{ Stillbirths* } & \multicolumn{2}{|c|}{ Early neonatal mortality } & \multicolumn{2}{|c|}{ Infant mortalityt } \\
\hline & & Multiple & Singleton & Multiple & Singleton & Multiple & Singleton \\
\hline \multirow[t]{10}{*}{ Under 1500} & 1982 & 97.2 & 197.3 & 241.4 & 252.9 & 314.8 & 334.9 \\
\hline & 1983 & 113.8 & 119.0 & 245.1 & 351.1 & 315.7 & 336.2 \\
\hline & 1984 & 101.0 & 178.5 & 260.4 & 235.7 & 344.9 & 308.9 \\
\hline & 1985 & 88.8 & 168.0 & 232.5 & 230.7 & 298.7 & 302.4 \\
\hline & 1986 & 96.5 & 169.4 & 241.4 & 219.9 & 324.3 & 296.1 \\
\hline & 1987 & 87.5 & 147.8 & 238.5 & 210.7 & 322.9 & 289.0 \\
\hline & 1988 & 81.7 & 139.8 & 233.8 & 214.7 & 317.6 & 297.8 \\
\hline & 1989 & 79.4 & 122.0 & 217.6 & 174.5 & 300.8 & 255.5 \\
\hline & 1990 & 80.3 & 131.8 & 214.0 & 169.7 & 289.2 & 247.9 \\
\hline & 1991 & 75.4 & 128.2 & 203.9 & 168.6 & 263.0 & 239.9 \\
\hline \multirow[t]{10}{*}{$1500-2499$} & 1982 & 17.6 & 33.3 & 7.6 & 18.1 & 17.1 & 34.0 \\
\hline & 1983 & 16.5 & 32.7 & 8.3 & 18.7 & 21.5 & 33.1 \\
\hline & 1984 & 14.8 & 32.5 & 8.6 & 16.7 & 21.2 & 31.0 \\
\hline & 1985 & 14.4 & 31.6 & 8.2 & 16.0 & 23.4 & 31.4 \\
\hline & 1986 & 16.3 & 28.7 & 9.5 & 15.0 & 23.8 & 29.8 \\
\hline & 1987 & 13.7 & 28.4 & 6.2 & 12.6 & 17.5 & 27.2 \\
\hline & 1988 & 13.0 & 29.1 & 8.1 & 12.5 & 21.5 & 28.5 \\
\hline & 1989 & 11.5 & 28.9 & 6.3 & 9.9 & 18.2 & 24.2 \\
\hline & 1990 & 11.3 & 27.6 & 4.2 & 8.7 & 12.3 & 21.5 \\
\hline & 1991 & 12.2 & 26.7 & 5.3 & 8.4 & 11.8 & 20.2 \\
\hline \multirow[t]{10}{*}{ Under 2500} & 1982 & 29.7 & 55.6 & 40.6 & 45.2 & 59.2 & 68.8 \\
\hline & 1983 & 33.3 & 64.3 & 45.7 & 36.0 & 68.0 & 69.6 \\
\hline & 1984 & 29.2 & 53.7 & 47.7 & 44.3 & 71.5 & 65.9 \\
\hline & 1985 & 26.7 & 51.5 & 42.9 & 43.4 & 66.0 & 66.0 \\
\hline & 1986 & 30.8 & 49.0 & 48.5 & 40.8 & 74.4 & 63.4 \\
\hline & 1987 & 27.0 & 46.3 & 45.5 & 39.1 & 69.2 & 62.3 \\
\hline & 1988 & 25.6 & 45.9 & 47.1 & 40.1 & 72.6 & 65.2 \\
\hline & 1989 & 23.4 & 43.3 & 41.2 & 33.2 & 64.8 & 56.9 \\
\hline & 1990 & 23.7 & 43.1 & 39.6 & 30.5 & 59.0 & 52.1 \\
\hline & 1991 & 23.1 & 41.7 & 37.9 & 29.9 & 53.1 & 49.6 \\
\hline \multirow[t]{10}{*}{2500 and over } & 1982 & 6.0 & 2.3 & 2.3 & 1.4 & 6.4 & 5.7 \\
\hline & 1983 & 3.6 & 2.2 & 2.8 & 1.3 & 9.8 & 5.3 \\
\hline & 1984 & 4.4 & 2.2 & 3.1 & 1.3 & 8.6 & 5.0 \\
\hline & 1985 & 6.0 & 2.2 & 3.1 & 1.2 & 8.1 & 5.0 \\
\hline & 1986 & 3.3 & 2.1 & 3.5 & 1.2 & 12.6 & 4.9 \\
\hline & 1987 & 4.1 & 2.0 & 2.4 & 1.1 & 10.7 & 4.9 \\
\hline & 1988 & 3.4 & 2.0 & 2.7 & 1.1 & 7.8 & 4.4 \\
\hline & 1989 & 3.8 & 2.0 & 1.7 & 0.9 & 6.4 & 4.1 \\
\hline & 1990 & 2.6 & 1.9 & 1.8 & 0.8 & 6.8 & 3.6 \\
\hline & 1991 & 3.3 & 2.0 & 2.8 & 0.7 & 6.4 & 2.9 \\
\hline \multirow[t]{10}{*}{ All birthweights } & 1982 & 19.9 & 6.0 & 26.0 & 4.6 & 38.0 & 10.1 \\
\hline & 1983 & 20.3 & 5.4 & 26.2 & 4.2 & 41.6 & 9.3 \\
\hline & 1984 & 18.0 & 5.4 & 26.8 & 3.9 & 42.1 & 8.7 \\
\hline & 1985 & 17.5 & 5.3 & 24.5 & 3.9 & 39.2 & 8.8 \\
\hline & 1986 & 18.7 & 5.0 & 28.1 & 3.7 & 46.0 & 8.5 \\
\hline & 1987 & 17.1 & 4.7 & 26.1 & 3.4 & 42.7 & 8.4 \\
\hline & 1988 & 15.4 & 4.6 & 26.7 & 3.3 & 42.5 & 7.9 \\
\hline & 1989 & 14.8 & 4.4 & 25.1 & 3.1 & 39.9 & 7.5 \\
\hline & 1990 & 14.4 & 4.4 & 24.3 & 3.0 & 37.5 & 6.9 \\
\hline & 1991 & 14.4 & 4.4 & 24.9 & 2.9 & 35.7 & 6.1 \\
\hline
\end{tabular}

* Rate per 1000 births.

† Rate per 1000 live births.

Source: OPCS Mortality Statistics, Series DH3

as "not stated," compared with 4\% in 1982 and from 1989 onwards, with less than $0.2 \%$ missing in the intervening years. For these reasons, rates of birthweight specific mortality in 1980 should be viewed with caution.

\section{Stillbirths}

Stillbirth rates for all births have been in decline since data collection began in 1928 . Separate data for stillbirths resulting from multiple births have been routinely available only from 1975 onwards. These data show a drop from 29.3 stillbirths per thousand births in 1975 , to 14.4 per thousand births in 1991 . Over the same period, the corresponding rates for singleton births decreased from 9.9 in 1975 to 4.4 in 1991 . The rates of stillbirth for both multiple and singleton births have recently begun to level off. In 1990 and 1991, only small decreases in rates were discernible. Nevertheless, stillbirth rates for multiple births are more than three times greater than those for singleton births, a ratio that has held constant since 1975.
As mentioned earlier, the information on the numbers of multiple and singleton births may be incomplete because of the laws concerning which fetal deaths should be registered. An analysis of twins born in 1975-78 with one twin stillborn, showed an unexpectedly high number of twin sets where the gestational age was given as 28 weeks. ${ }^{4}$ The article suggested that this may mean that some of these twins may have been born earlier than 28 weeks, but recorded as 28 weeks on the stillbirth certificate so that both babies could be registered.

\section{Infant mortality}

Infant mortality rates have also shown a consistent decline since 1928, and since 1975 the overall infant mortality rate has fallen by half. Infant mortality for multiple births decreased from 75.2 deaths per thousand live births in 1975 to 35.7 per thousand births in 1991. Over the same period, the corresponding death rates for singletons decreased from 14.3 in 1975 to 6.1 in 1991 . Nevertheless, infant mortality rates for multiple births are still more than five times higher than those for 


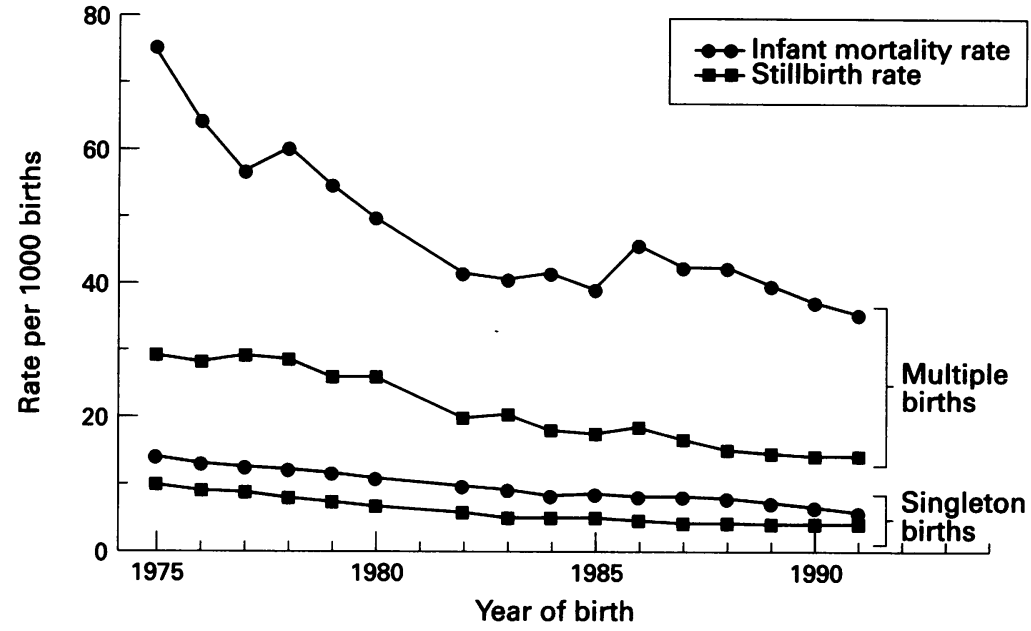

Figure 5 Stillbirths and infant mortality rates, multiple and singleton births, England and Wales, 1975-91. Source: OPCS annual statistics, Series DH3, England and Wales. NB: rates for 1981 are estimated.

singleton births. In 1949/50, when overall infant mortality rates were over three times the rates in 1991 , the rate of mortality for multiple births was more than four times that for singletons. ${ }^{25}$ This change in infant mortality rates for multiple births and for singletons is shown in fig 5 .

As with stillbirths, birthweight specific infant mortality rates are available only for 1980 onwards. Lower birthweight babies from multiple births tend to have only slightly higher infant mortality rates than low birthweight singleton births. For babies weighing under $1500 \mathrm{~g}$, the odds ratio was 1.54 , with a $95 \%$ confidence interval of 1.35 to 1.75 . At higher birthweights, multiple births tend to have higher mortality than singletons (table 6). Overall, the odds ratio for mortality in the first year for a baby from a multiple birth compared with a baby from a singleton birth was 5.34, with a $95 \%$ confidence interval of 4.40 to 5.82 .

In general, there has been a greater percentage reduction in infant mortality rates for babies from lower birthweight groups than in those from higher birthweight groups. Nevertheless, mortality rates for babies weighing

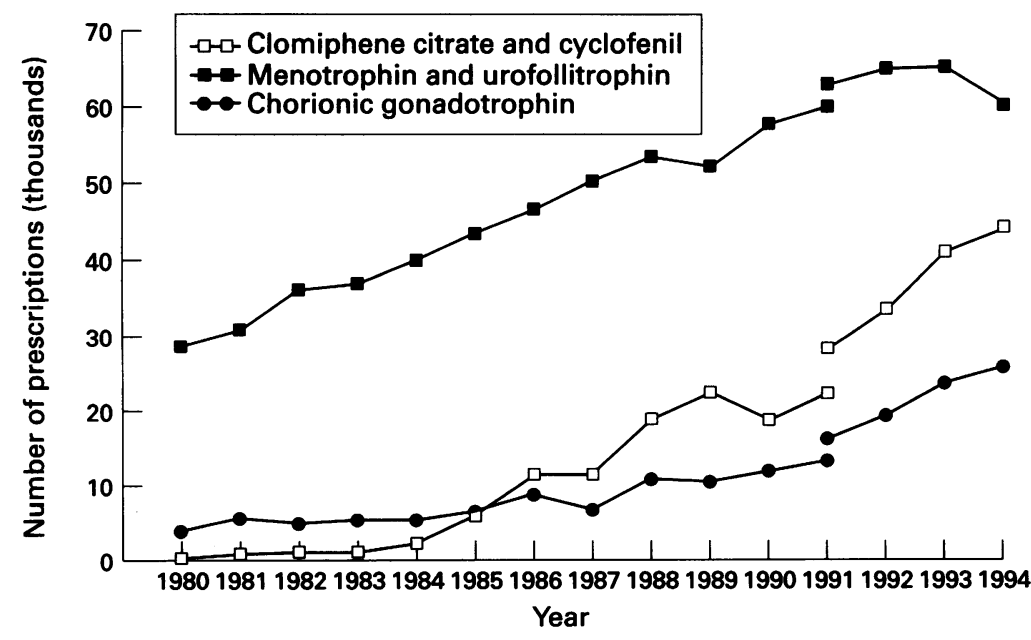

Figure 6 Numbers of prescriptions dispensed for drugs used to manage subfertility, England, 1980-4. Source: Department of Health. NB: Data up to 1990 are not consistent with data from 1991 onwards. Figures for the period $1980-90$ are based on fees and $a$ sample of 1 in 200 prescriptions dispensed by community pharmacists and appliance contractors only. Figures from 1991 are based on items and also cover prescriptions dispensed by dispensing doctors and items submitted by prescribing doctors for items personally administered. under $2500 \mathrm{~g}$ are still much higher than those for babies weighing $2500 \mathrm{~g}$ or more.

\section{Neonatal mortality}

Neonatal death rates have also been in decline since 1975, although overall rates of neonatal death continue to be higher for multiple births. Babies from multiple births are almost eight times more likely than singletons to die in the neonatal period. As with stillbirths, there seems to be a considerable slowing in the decline in rates of neonatal death for multiple births in recent years. Similar trends have been observed in Scotland. ${ }^{6}$ Over the past decade there have been small decreases in birthweight specific neonatal mortality rates in each group of babies from multiple births, while the fall among singletons has been more noticeable.

\section{Postneonatal mortality}

It is difficult to tell what is happening with postneonatal death rates for multiple births due to the small number of events and the lack of any clear trend. With developments in neonatal care some deaths, which in the past would haven occurred earlier, are now being postponed to the postneonatal period.

\section{Sex differences in twin mortality}

Mortality rates within like sex and unlike sex twins have shown a consistent pattern of change over the past decade. Mortality rates are consistently higher for like sex twins than for twins of unlike sex. Male twin pairs also seem to have slightly higher mortality rates than female twin pairs, with an odds ratio for infant mortality of 1.67 (95\% confidence interval of 1.34 to 2.04 ). The picture is similar for neonatal mortality. This is not surprising as overall mortality rates for boys tend to be higher than those for girls.

In 1975, there were 37 stillbirths of like sex twins per thousand corresponding births. This more than halved to 16 stillbirths per thousand births in 1991. The numbers of stillbirths among unlike sex pairs are considerably smaller, and hence the rates of stillbirths over the same period have fluctuated considerably. In 1975, there were 12 stillbirths of unlike sex twins per thousand corresponding births. This increased to a maximum of 19 in 1978, and then fell to a low of 7 in 1990. In 1991, the rate had increased again to 10 stillbirths per thousand. Similar trends can be seen in neonatal mortality and infant mortality for like and unlike sex twins, though the smaller numbers result in wider fluctuations in rates and as a result, these trends are less apparent.

These data for England and Wales are compatible with those in a population based study of twin perinatal mortality in Sweden over the period 1973 to $1985 .^{26}$ This study also found that like sexed twins had a significantly higher perinatal mortality than unlike sex twins. This difference was still apparent after stratifying for year of delivery and birthweight.

TRENDS IN IMPACT AND AVAIIABILITY OF DRUGS, AND PROCEDURES FOR SUBFERTILITY

Limited data are available on the outcome of maternities resulting from medical management of subfertility, so it is difficult for an 
accurate assessment to be made of the impact of these procedures on multiple birth rates. Nevertheless, the data do suggest that there may be some association between the use of the procedures and the recent rise in the proportion of multiple births in England and Wales.

Department of Health data for prescriptions dispensed in England (fig 6) show a substantial increase over the past decade in the numbers of prescriptions of drugs which could be used for the management of subfertility. (Department of Health. Prescription analysis of hypothalamic and pituitary hormones $\mathcal{E}$ antioestrogens 19801994. Unpublished data, 1995). The association between the increase in the dispensing of these drugs and the increased rate of multiple maternities, especially triplets, is not necessarily causal, but it is likely that there is a link. The rise in the rate of a multiple maternity following the use of such drugs has been widely reported in previous studies, ${ }^{27}$ although the sizes of the reported effects vary widely. In particular, the reason for which the drugs are prescribed is not recorded

Nevertheless, data from other sources suggest a similar conclusion. Data from the HFEA, which include an unknown proportion of births registered outside England and Wales, show that almost $30 \%$ of live births resulting from IVF are from a multiple maternity. ${ }^{20} \mathrm{~A}$ survey of 1092 births in Great Britain resulting from assisted conception between 1978 and 1987 , found that $19 \%$ of the resultant deliveries were sets of twins and $4 \%$ were sets of triplets or other higher order births. ${ }^{16}$

The National Study of Triplet and Higher Order Births ${ }^{2}$ covered higher order multiple births in England and Wales in the years 1980 to 1985 , excluding births in 1981 when multiple births were not coded by OPCS. This covered a period when techniques for assisted conception had only recently become available. Thus they accounted for relatively few births before 1985 . In the survey as a whole, $63 \%$ of sets of all triplets were conceived spontaneously, 33\% after the use of ovarian stimulants and only $4 \%$ after using assisted conception.

In contrast, a survey by the British Association of Perinatal Medicine of triplet and higher order births in 1989 found that assisted reproduction was a major cause of triplet and higher order births. ${ }^{27}$ Among 141 sets of triplets whose method of conception was ascertained, $33 \%$ were conceived spontaneously, $31 \%$ after the use of ovarian stimulants and $35 \%$ using assisted conception.

Comparison of data from these two national surveys suggest that not only assisted conception, but also drugs used in the medical management of subfertility and assisted conception, may have contributed to the rise in the rate of triplet and higher order births ${ }^{5}$ during the 1980 s. Although assisted conception made a major contribution to the increase in the triplet rate, there was also an increase in the rate attributable to the ovarian stimulants. ${ }^{5}$ Because routine data on the use of ovarian stimulants and assisted conception are not specifically linked to birth outcomes in England and Wales in a way which permits comparisons with the overall changes in the rates of multiple births, it is difficult to comment on the contribution of more recent developments in the use of assisted conception procedures to the increases observed in multiple birth rates. Nevertheless, evidence from previous studies suggests that increasing use of ovarian stimulation and assisted conception contributed to the overall increase in the numbers of multiple births in England and Wales.

\section{Discussion}

The increase in the multiple birth rate in England and Wales since 1980 has been striking. As in other developed countries, the rates of multiple births have also risen in Scotland and Northern Ireland.

Similar comparisons can be made with other developed countries of the very dramatic increases in the rates of triplet and higher order births. Although their overall numbers are relatively small, 268 sets of triplet and other higher order births in 1994 in England and Wales and the very considerable problems they pose to their families and to the health and social services, make the increase a matter for concern. ${ }^{28}$

A study of triplet and higher order births in the state of Victoria in Australia, ${ }^{11}$ where the rate was more than three times that for England and Wales, with 1.09 triplets and other higher order births per thousand maternities by 1990 , found that the proportion of these maternities that resulted from IVF or GIFT was $42 \%$. In the other states of Australia the rates of triplet and higher order multiples had increased at 1.8 times the rate for Victoria. It was estimated that IVF and GIFT contributed about $43 \%$ of these conceptions between 1985 and 1989.

Data from the east Flanders prospective twin survey $^{12}$ showed an even more dramatic increase in multiple birth rates over the period 1976 to 1992 in a small population whose spontaneous twin rate was declining. Most of the increase was attributed to ovarian stimulants, although assisted conception had begun to have a major role by the early 1990 s. Similar conclusions were reached in a review of time trends in the United States ${ }^{29}$ where rates were not as high as in east Flanders.

A review of French routine data ${ }^{13}$ reported that the rate of triplet and other higher order births had reached 0.44 per thousand maternities in 1989. It was estimated that between 1985 to 1989 , almost a half of triplet deliveries in France resulted from the use of drugs for ovulation induction treatments without assisted conception, and a quarter arose from assisted conception. Nevertheless, the authors concluded that there was a need to estimate more precisely the rate of multiple maternities associated with drugs and procedures for the medical management of subfertility.

When the rate of multiple births reached a low level in the mid 1970s, no clear hypothesis was advanced for the decrease. ${ }^{30}$ This contrasts with the recent rise which has been widely attributed to assisted conception. As we have shown, the evidence suggests that ovarian stimulants and, from the late 1980s onwards, 
assisted conception, had a considerable impact on the rate of multiple births in England and Wales. To quantify this, however, data that explicitly relate the use of these procedures to their outcome are needed. Although it is clear that the increasing use of drugs used in the medical management of subfertility, and assisted conception, have made a major contribution to the increases observed, other factors may play a part. In particular, the impact of delayed childbearing should not be ignored.

One gap in the information about multiple maternities has recently been filled. The Human Fertilisation and Embryology Act of 1990 amended the 1967 Abortion Act to make it clear that selective termination of one or more, but not all, of the fetuses in a multiple pregnancy could be performed, provided the requirements of the 1967 Act are fulfilled. These terminations have been notifiable since 1 April 1991. There were 37 selective terminations notified in 1992 and 32 in $1993 .^{31}$

THE NEED FOR BETTER DATA

More appropriate data of high quality are needed. This applies both to data about the use of drugs and procedures, and to data about singleton and multiple births and their mortality. To answer more direct questions about treatments of subfertility and its outcomes, data would probably need to be specifically collected for this purpose.

As we have pointed out earlier, there are major gaps in the data about assisted conception collected by the HFEA, and a fuller picture can be obtained only through special surveys. There is also no person based routine collection of data about the use of drugs for the medical management of subfertility without assisted conception. No detailed data are collected at national level about care given in outpatient clinics in NHS hospitals, and there is no routine system for aggregating nationally the data collected in individual general practices. Furthermore, data are not collected about the use of drugs and procedures for the management of subfertility in the private sector.

Proposals are being developed by the British Fertility Society and the Royal College of Gynaecologists for a national audit of infertility treatment, but these have not yet been implemented. It is disappointing that these new drugs and procedures were introduced without first setting up adequate systems for monitoring their use and outcome. Health authorities vary in the extent to which they fund subfertility services under the NHS, and information on which such decisions are based is patchy. ${ }^{32}$

Although there are more comprehensive data about births and infant mortality, there are still aspects which need improvement. Some of these were identified in the earlier article. ${ }^{4}$ For example, birth order within a multiple birth is still not recorded by OPCS; the time of birth is recorded only when there are two or more live births within a multiple birth; and the time of birth is not recorded for any stillbirth. As mentioned earlier, parity is still not coded for births outside marriage. Although a white paper produced by the OPCS in $1990^{33}$ proposed recording clinical parity for all births, there has yet to be legislation to do so.

The change in the form used to certify the causes of stillbirth and neonatal death in 1986 led to the availability of much more detailed data, but created the need for a way of classifying it. A hierarchical classification has been developed for grouping data collected on the new form of neonatal death certificate ${ }^{34}$ and this is now being extended to stillbirths. Analyses of causes of stillbirths and neonatal deaths among singleton and multiple births have yet to be published and few analyses have been done. Improvement is also needed in the quality of cause of death information recorded by doctors on death certificates.

Little progress has been made with obtaining data on the gestational age of live births from the Maternity Hospital Episode System because of the continuing incompleteness and the poor quality of data. ${ }^{55-37}$ Progress with the corresponding system in Wales has been equally disappointing. Nevertheless, in Wales birth notification data are now analysed at a national level. This approach might provide an alternative way to tackle problems in England. Although the increasing survival of low and very low birthweight babies from multiple births has been welcomed, there is still concern that this may be accompanied by increases in the prevalence of disability among the survivors. Unfortunately, there is a dearth of data at a national level about the morbidity of children in general or these children in particular. ${ }^{5-38}$ Since the National Study of Triplet and Higher Order Births ${ }^{2}$ better methods of follow up have been developed. ${ }^{39}$ Nevertheless, the study still pointed to a relatively high prevalence of disability among triplets compared with the population as a whole. The small numbers make it difficult to make precise estimates of the prevalence of disability in triplets, even with a special study in one country..$^{40}$ To look at larger numbers of events, an international study is now examining the incidence of cerebral palsy among multiple births as a whole.

Taken as a whole, however, the available data on infertility treatment and its outcome, as well as data about multiple births and longer term outcomes, are patchy and incomplete. Given the continuing rise in the multiple birth rate, it is an appropriate time for action to be taken to ensure that better data are available to assess causes and to monitor outcomes.

We thank Beverley Botting, Penny Babb, Eva Alberman, Patsy Bailey, Beverley Petterson, Pat Doyle, Beatrice Blondel, and colleagues in the National Perinatal Epidemiology Unit, the Office of Population Censuses and Surveys, and elsewhere for their helpful advice and comments.

The Office of Population Censuses and Surveys merged with the Central Statistical Office to become the Office for National Statistics on 1 April 1996.

The authors are funded by the Department of Health.

1 OPCS. Mortality statistics, England and Wales, Series DH3. Perinatal and infant: social and biological factors. London: HMSO, published annually. 
2 Botting B, Macfarlane AJ, Price F, eds. Three, four and more: a study of triplet and higher order births. London: HMSO, 1990.

3 MacGillivray I, Campbell D, Thompson B, eds. Twinning and twins. Chichester: John Wiley, 1988.

4 Botting B, Macdonald Davies I, Macfarlane AJ. Recent trends in the incidence of multiple births and associated trends in the incidence of multiple births
mortality. Arch Dis Child 1987;66:941-50.

5 Macfarlane AJ, Mugford M, Johnson A, Garcia J. Counting the changes in childbirth: Trends and gaps in national statistics. the changes in childbirth:Trends and gaps in national statistic

6 Scottish Office, Home and Health Department. Report on maternal $\mathcal{E}$ perinatal deaths in Scotland 1986-1990. Edinburgh: HMSO, 1994:23-8.

7 Keith L, Papiernik E, Luke B. The costs of multiple pregnancy. Int $\mathcal{F}$ Obstet Gynecol 1991;36:109-14.

8 National Center for Health Statistics. Vital and Health Statistics. Health and demographic characteristics of twin births United States. Washington, DC: NCHS,1988, series 21 , number 50 .

9 Bender R, Ford D. Births in Canada, 1992. Health Reports 1993;5:341-7.

10 Imazaizumi Y. Triplets and higher order multiple births in Japan. Acta Genet Med Gemellol 1990;39:295-306.

11 Jonas $\mathrm{H}$, Lumley J. Triplets and quadruplets in Victoria between 1892 and 1990: The impact of IVF and GIFT on rising birthrates. Med ₹ Aust 1993;158:659-63.

12 Derom C, Derom R, Vlietinck R, Maes H, Van de Berghe $H$ Iatrogenic multiple pregnancies in East Flanders, Belgium. Assist Reprod Technol 1993;60:493-6.

13 Tuppin $P$, Blondel B, Kaminski M. Trends in multiple deliveries and infertility treatments in France. $\mathrm{Br} \mathcal{F}$ Obste Gynaecol 1993;100:383-5.

14 Parazzini F, Tozzi L, Mezzanotte G, Bocciolone L, Vecchia C, Fedele L, Benzi G. Trends in multiple births in Italy: 1955-1983. Br F Obstet Gynaecol 1991; 98:535-9.

15 AIWH National Perinatal Statistics Unit, Fertility Society of Australia. Assisted Conception, Australia and New Zealand, 1991. Sydney: AIWH National Perinatal Statistics Unit, 1993.

16 MRC Working Party on Children Conceived by In Vitro Fertilisation. Births in Great Britain resulting from Fertilisation. Births in Great Britain resuld

17 Allen G, Bracken MB (ed). Perinatal epidemiology. Oxford: Oxford University Press, 1984.

18 Dean AG, Dean JA, Coulombier D, Brendel KA, Smith DC Burton AH, et al. Epi Info, Version 6: a word processing, database, and statistics program for epidemiology on microcomputers. Atlanta, Georgia, USA: Centers for Disease Contro and Prevention, 1994.

19 OPCS. Birth statistics, England and Wales, Series FM1. London: HMSO, published annually.

20 Human Fertilisation and Embryology Authority. Annual reports, 1991-1994. London: HFEA, published annually.

21 Weinberg W. Beitrage zur Physiologic and Pathologie der Mehrlingsgeburten beim Menschen. Pflugers Arch 1901; 88:346-430.
22 Husby H, Holm N, Gernow A, Thomsen S, Kock K, Gurter $H$. Zygosity, placental membranes and Weinberg $s$ rule in Danish consecutive twin series. Acta Genet Med Gemellol 1991;40:147-52.

23 James W. The current status of Weinberg's differential rule. Acta Genet Med Gemellol 1992;41:33-42.

24 Bulmer M. Is Weinberg's method valid? Acta Genet Med Gemellol 1976;25:25-8.

25 Macfarlane AJ, Mugford M. Birth counts: Statistics of pregnancy and childbirth. Volumes $1 \mathcal{E} 2$. London: HMSO, 1984 .

26 Rydhström $H$. The effects of maternal age, parity, and the sex of twins on twin perinatal mortality. A population sex of twins on twin perinatal mortality. A populatic
based study. Acta Genet Med Gemellol 1990;39:401-8.

27 Levene MI, Wild J, Steer P. Higher multiple births and the modern management of infertility in Britain for the British Association of Perinatal Medicine. Br $\mathcal{F}$ Obstet Gynaecol 1992;99:607-13.

28 Mugford $M$, Henderson J. Resource implications of multiple birth. In:Ward RHT, Whittle M, Patel N, Multiple pregnancy. Proceedings of the Thirtieth RCOG Study Group. London: Royal College of Gynaecologists, 1995.

29 Kiely J, Kleinman J, Kiely M. Triplets and higher-order births: Time trends and infant mortality. $A m \mathcal{F}$ Dis Child 1992;146:862-8

30 Anonymous. Worldwide decline in dizygotic twinning rates. BMF 1976;i: 1553 .

31 OPCS. Abortion Statistics 1993, Series $A B$ No 20. London: HMSO, 1995.

32 The Management of Subfertility. Leeds: School of Public Health, Leeds University, 1992. (Effective Health Care Bulletin No 3.)

33 OPCS. Registration: proposals for change. Cm 939. London: HMSO, 1990.

34 Alberman E, Botting B, Blatchley N, Twidell A. A new hierarchical classification of causes of infant deaths in England and Wales. Arch Dis Child 1994;70:403-9.

35 Sackville T. Caesarean births. In: Written answers. Hansard, Vol. 243, Col. 519, May 181994

36 Sackville T. Health statistics. In: Written answers. Hansard, Vol. 248, Col. 820, October 271994.

37 Middle C, Macfarlane AJ. Recorded delivery. Health Service fournal 1995;105:27.

38 National Perinatal Epidemiology Unit. Disability and perinatal care: measurement of health status at two years. Report of two working groups convened by the NPEU and Oxford Regional Health Authority. Oxford: NPEU, 1994.

39 National Perinatal Epidemiology Unit. Developing a national monitoring Ssstem to assess child health. Stage 1: Feasibility study in the Oxford Region. Preliminary Report. Oxford: NPEU, 1994.

40 Petterson B, Nelson K, Watson L, Stanley F. Twins, triplets, and cerebral palsy in births in Western Australia in the and cerebral palsy in births in
1980 s. BMF 1993;307:1239-43. 